\title{
Systemic granuloma in goldfish caused by a Dermocystidium- like aetiological agent
}

\author{
J. H. Landsberg ${ }^{1, *}$, I. Paperna $a^{2, * *}$ \\ ${ }^{1}$ Laboratory for Fish Disease Research, Nir David, 19150, Israel \\ ${ }^{2}$ Department of Animal Sciences, Faculty of Agriculture of the Hebrew University of Jerusalem, Rehovot, 76-100, Israel
}

\begin{abstract}
Systemic infection by a Dermocystidium-like parasitic organism caused visceral granuloma and mortality in farmed goldfish Carassius auratus. Granulomatous nodules occurred mainly in the kidney and spleen and later spread to other visceral organs. Macrophages within the granulomata contained 1 to 20 uninuclear or 1 plurinuclear parasite, sometimes located within a parasitophorous vacuole. The granulomata gradually became necrotic. Parasites were gradually displaced to the periphery and disappeared within 1 to $2 \mathrm{mo}$. The granulomata however, persisted and continued to expand after the elimination of the presumed aetiological agent. Granulomata regressed into fibrotic capsules 6 to 9 mo after disease onset.
\end{abstract}

Over the past few years, outbreaks of systemic granuloma in pond-reared goldfish have occurred in several commercial farms in Israel. Such outbreaks have resulted in sporadic mortality, and in several instances mass mortality, of affected fish. In this research note we introduce and describe a systemic granulomatous disease of goldfish and its aetiological agent.

Material and methods. Since the recognition of a systemic granulomatous condition in goldfish in 1982 ('Goldfish Kidney Granuloma'; Landsberg \& Paperna 1985), farm-reared goldfish, as well as common and koi carp, have been periodically checked for the presence of nodules in the viscera. At 3 affected fish

\footnotetext{
- Present address: Florida Marine Research Institute, 100 Eighth Avenue S.E., St. Petersburg, Florida 33701-5095, USA

- Addressee for correspondence
}

farms, comet ( $\mathrm{n}=26,6$ to $21 \mathrm{~cm}$ total length, $\mathrm{TL}$ ), fantail ( $n=31,6$ to $8 \mathrm{~cm}$ TL) and calico fantail $(n=19$, 4 to $8 \mathrm{~cm} \mathrm{TL}$ ) varieties of goldfish were examined in late spring 1984, along with common carp $(\mathrm{n}=40,5$ to $17 \mathrm{~cm} \mathrm{TL}$ ) and koi carp ( $\mathrm{n}=31,6$ to $14 \mathrm{~cm}$ TL). Samples were taken from the head and trunk kidneys, liver, spleen and heart for the following analyses: (1) fresh squashed tissue was directly examined by Nomarski interference microscopy; (2) smears were air-dried and methanol-fixed for Giemsa stain; (3) samples were fixed in $10 \%$ neutral buffered formalin for histology. Fixed tissue was embedded in glycol methacrylate (Lulham 1979); 3 to $4 \mu \mathrm{m}$ sections were made using a JB 4 Sorval glass knife microtome and stained in Meyer's Haemalum eosin (MH-E) or PAS.

Results. Since 1982, systemic granuloma has been reported in comet, fantail and calico fantail varieties of goldfish, but has not been found in carp or koi carp in any farms in Israel.

External gross signs: Exophthalmia, raised scales and swollen abdomen, occurring only in advanced cases.

Gross pathology: Grey-white nodules appear initially in the trunk kidney and then spread to the head kidney and spleen. In late infections 0.5 to $3.0 \mathrm{~mm}$ nodules also occur in other visceral organs, notably the liver, mesenteries and heart. Both kidneys and spleen swell; the trunk kidney sometimes swells so extensively that it presses against the side of the abdominal body wall, resulting in haemorrhagic ulceration, or even in the wall's perforation.

Microscopy: Lesions were primarily characterized by well-circumscribed granulomata of hypertrophic 
macrophages (Figs. 1 \& 2) infected with 1 to 10 (exceptionally up to 20 ) round to oval, 2.0 to $3.5 \times 2.5$ to $5.0 \mu \mathrm{m}$ ( $\mathrm{n}=15$ in a fresh preparation) uninuclear Dermocystidium-like organisms (Figs. 3, 4 \& 5), or with one, 5 to $10 \times 4$ to $7 \mu \mathrm{m}(\mathrm{n}=5)$ plurinuclear parasite (Fig. 6). Some uninuclear forms contained a vacuole (Fig. 6, v). In part of the infected cell, parasites were located within a parasitophorous vacuole. Parasite nuclei multiplied by asychronous successive binary divisions (Fig. 6, b). Larger nodules contained a necrotic core of PAS-positive ground substance which was fringed by infected cells and an outer layer of uninfected fixed macrophages (epithelioid), and circumscribed by infiltrating macrophages (monocytes), lymphocytes and a layer of fibroblasts (Fig. 2). Later-stage granulomata were free of parasitized cells (Figs. $7 \& 8$ ), eventually becoming fibroblastencapsulated necrotic nodules (Fig. 9).

Pathogenesis: Lesions containing infected macrophages (Figs. $1 \& 2$ ) were found in fish (in both $0+$ and $1+$ age classes) from May through July. Lesions in fish examined after July/August were parasite-free. Nonetheless, granuloma formation progressed and led to morbidity throughout autumn (Fig. 7). Fibroblastencapsulated necrotic nodules were detected in fish viscera throughout the winter and following spring (Fig. 9)

Discussion. The presumed aetiological agent detected in goldfish affected by visceral granuloma was very similar to Dermocystidium macrophagi or the Dermocystidium-like organisms which cause a similar systemic granulomatous disease in salmonids (McVicar \& Wootten 1980, Van de Moer et al. 1986, Hedrick et al. 1989) and in carp (Kovacs-Gayer et al. 1986). Organisms similar to those presently reported from goldfish were detected in granuloma-affected goldfish in the USA, and following light and electron microscopic study were regarded as hartmanellid amoebae (Voelker et al. 1977). However, no conclusive evidence has as yet been provided regarding the classification of these organisms. Their taxonomic affinity remains controversial as does their relationship with other organisms termed Dermocystidium causing integumentary infections in fish (Cervinka et al. 1974, Wootten \& McVicar 1982) and oysters (D. marinum $=$ Perkinsus spp.; Perkins 1974). Ultrastructural affinities of the integumental $D$. salmonis as reported recently by Olson et al. (1991) are convincingly different from the causative agent, also named Dermocystidium, of the salmonid systemic granulomatosis as described by Van de Moer et al. (1986) and Hedrick et al. (1989).

The absence of infection in common and koi carp in Israel, even when reared in the same pond, suggests that the organisms described by Kovacs-Gayer et al. (1986) from carp are a different species from that found in goldfish. The pathogenesis of the disease in goldfish is characterized by restriction of the aetiological agent to the early stage of the disease (the acute stage?) while granuloma formation persists (the chronic phase?). This type of pathogenesis has not to date been reported in salmonid and carp systemic infections.

There are several reports of multiple granulomata with unknown aetiology in goldfish viscera (Schlumberger 1950, Stolk 1956, Wakabayashi et al. 1969, Munkittrick et al. 1985). Although a wide range of causative agents (including bacteria and fungi) are known to produce granulomatous changes in fish kidneys (Bendele \& Klontz 1975), some of these reported conditions could have initially been induced by Dermocystidium-like organisms.

Figs. 1 to 9. Carassius auratus. Fig. 1. Granuloma in goldfish trunk kidney containing hypertrophic macrophages (P) infected with Dermocystidium-like organisms (arrow) and circumscribed by fibroblasts (F). Histology, MH-E, $\times 800$. Fig. 2. Granuloma in trunk kidney with necrotic core (NC). fringed with infected macrophages (P) and an outer layer of epithelioid (E), and circumscribed by infiltrating macrophages (monocytes) and lymphocytes (M) and a layer of fibroblasts (F). Histology, MH-E, $\times 400$. Figs. 3 to 5. Enlarged views of infected macrophage from the trunk kidney. N: Macrophage nucleus; arrows. uninuclear parasites. Fig. 3, live, in Nomarski interference illumination, ×3000; Fig. 4, Giemsa stained, $\times 1500$; Fig. 5, histology, MH-E, $\times 1000$. Fig. 6. Macrophages from the periphery of granuloma with necrotic core containing uninuclear, binuclear (a), dividing, trinuclear (b) and plurinuclear (c) parasites. Some of these are contained within a parasitophorous vacuole (arrow). Some uninuclear forms contain a vacuole $(v)$. Histology, MH-E, $\times 1275$. Fig. 7. Parasite-free granulomata from goldfish trunk kidney with a necrotic core $(\mathrm{NC}$ ) and a fibroblast-infiltrated superficial layer (F). Histology, $\mathrm{MH}-\mathrm{E}, \times 214$. Fig. 8 . Enlarged view of the periphery of a parasite-free nodule. Histology, MH-E, $\times 1000$. Fig. 9. Residual fibroblast-encapsulated (F) necrotic nodule $(\mathrm{NC})$. Histology, MH-E, $\times 800$ 
won

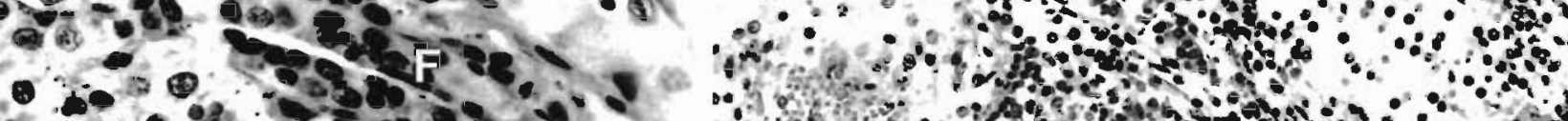

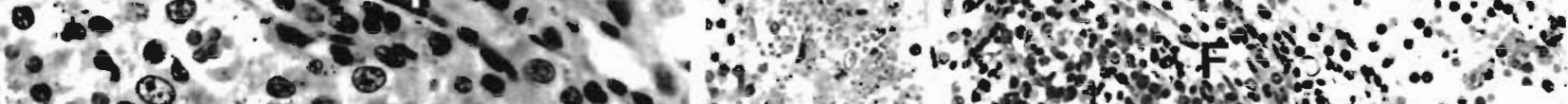
- $300^{2}$ -

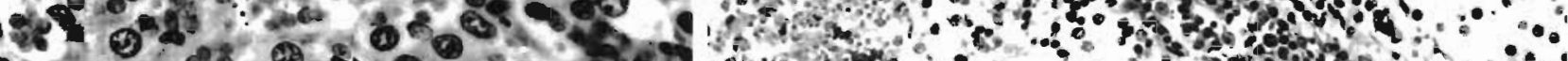

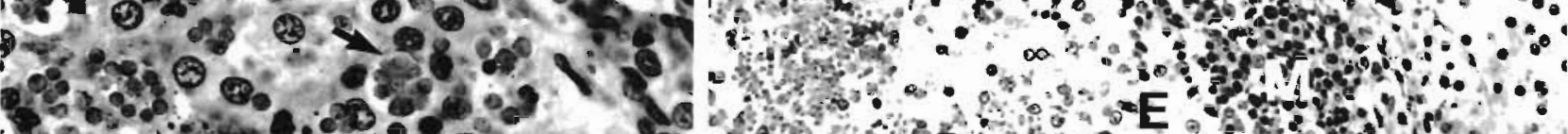
$39{ }^{3}$ - P

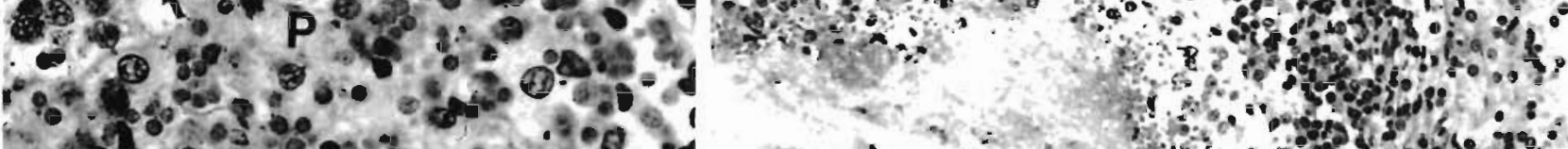

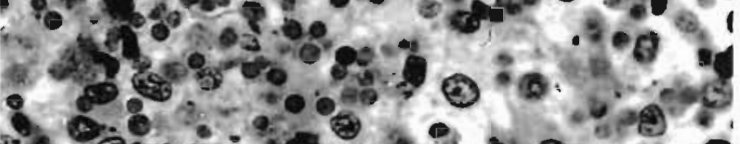

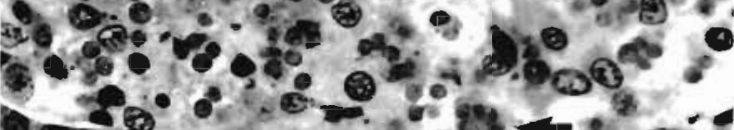

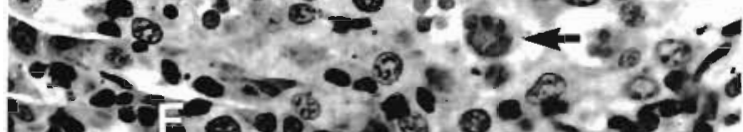
8 S

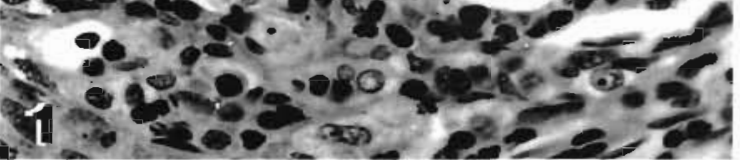

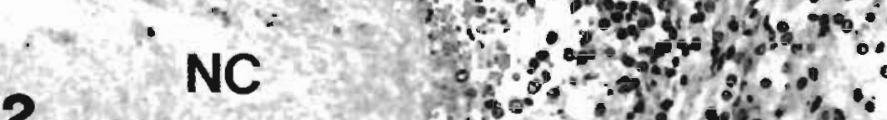
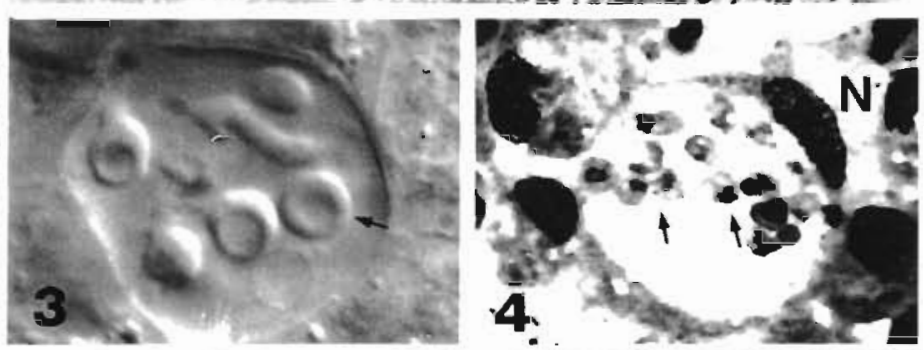

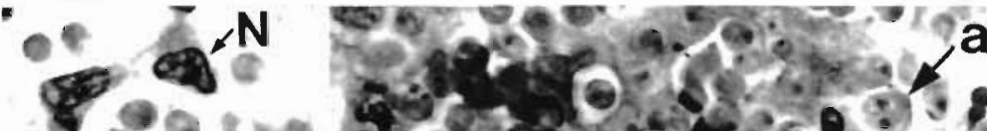

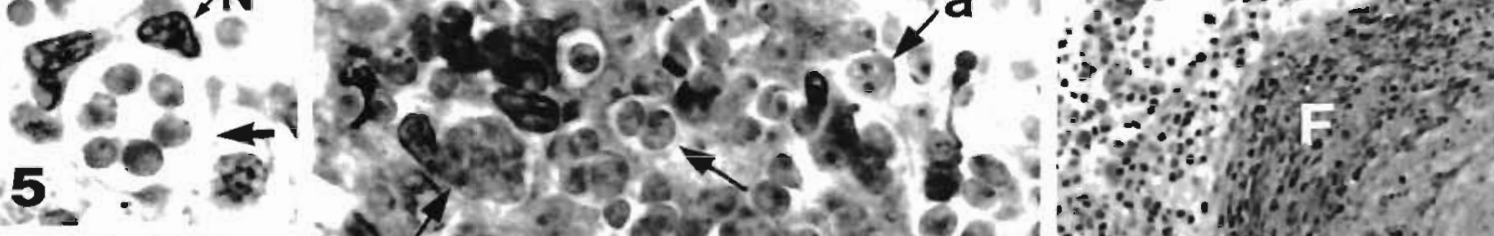

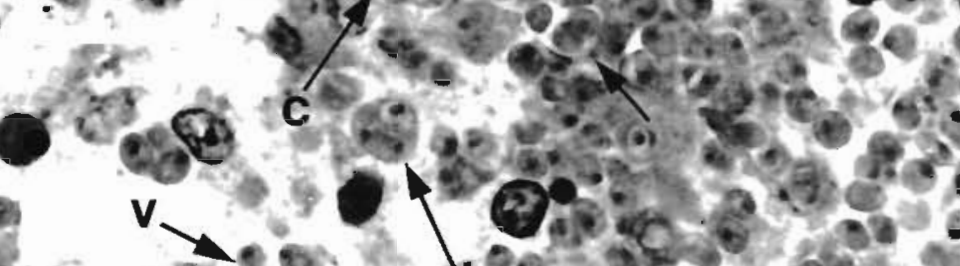

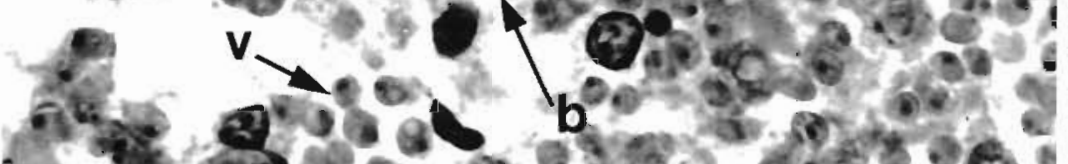

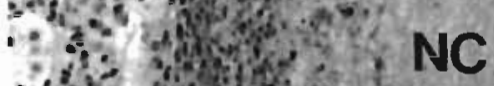

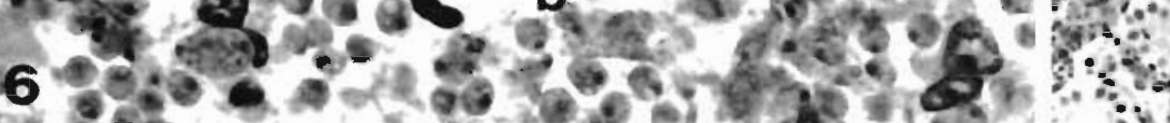
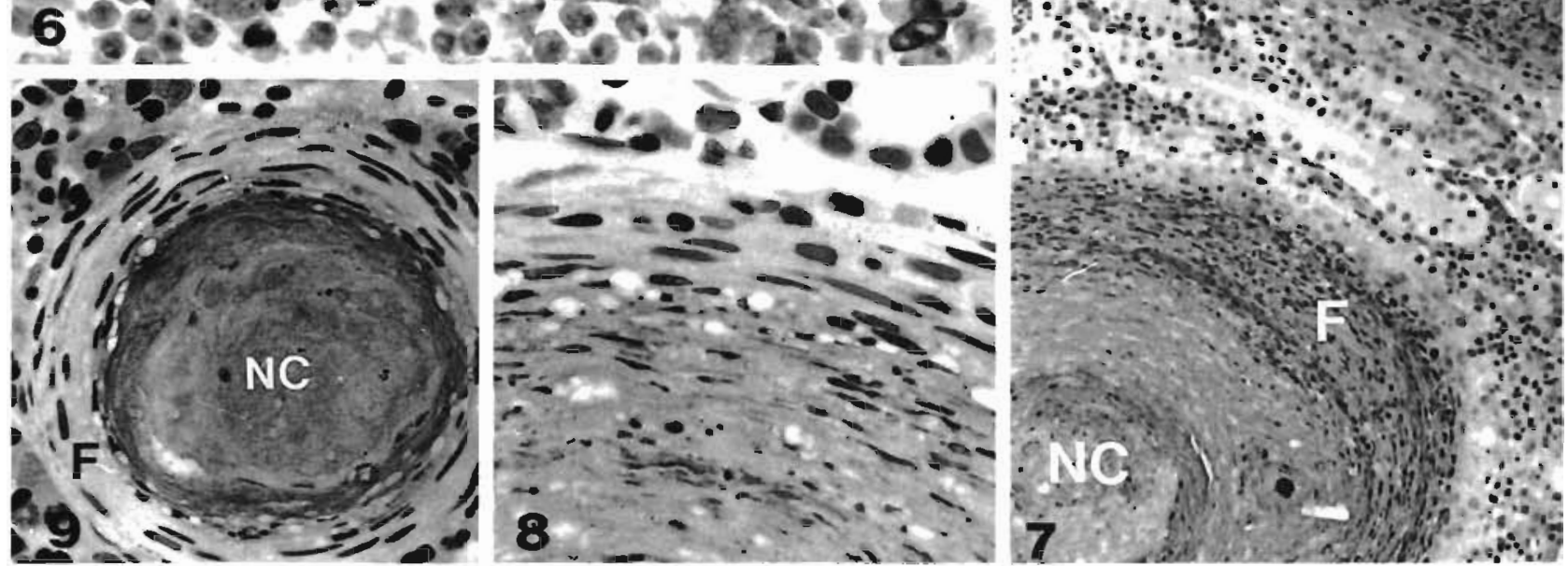


\section{LITERATURE CITED}

Bendele, R. A., Klontz, G. W. (1975). Histopathology of teleost kidney diseases. In: Ribelin, W. E., Migaki, G. (eds.) The pathology of fishes. University of Wisconsin Press, Madison, p. 365-382

Cervinka, S., Vitovec, J., Lom, J., Hoska, J., Kubu, F. (1974) Dermocystidiosis - a gill disease of the carp due to Dermocystidium cyprini n. sp. J. Fish Biol, 6:689-699

Hedrick, R. P., Friedman, C. S., Modin, J. (1989). Systemic infection in Atlantic salmon Salmo salar with a Dermocystidium-like species. Dis. aquat. Org. 7: 171-177

Kovacs-Gayer, E., Csaba, G., Ratz, F., Bekesi, L., Szakolczai, J. (1986). Granulomatosis of common carp (Cyprinus carpio L.). Bull. Eur. Ass. Fish Pathol. 6: 72-75

Landsberg, J. H., Paperna, I. (1985). Parasite induced kidney granuloma in the goldfish Carassius auratus. European Ass. Fish Pathol. 2nd Int. Conf., Montpellier, France. Abstract A45, p. 72

Lulham, C. N. (1979). Glycol methacrylate embedding for light microscopy. J. Histotechnol. 2: 68-71

McVicar, A. H., Wootten, R. (1980). Disease in farmed juvenile Atlantic salmon caused by Dermocystidium sp. In: Ahne, W. (ed.) Fish diseases. Third COPRAQ-Session, SpringerVerlag, Berlin, p. 165-173

Munkittrick, K. R., Moccia, R. D., Leatherland, J. F. (1985) Polycystic kidney disease in goldfish (Carassius auratus)

Responsible Subject Editor: W. Körting, Hannover, Germany from Hamilton Harbour, Lake Ontario, Canada. Vet. Pathol. 22: 232-237

Olson, R. E., Dungan, C. F., Holt, R. A. (1991). Water-borne transmission of Dermocystidium salmonis in the laboratory. Dis. aquat. Org. 12: 41-48

Perkins, F. O. (1974). Phylogenetic consideration of the problematic thraustochytriaceous-labyrinthulid-Dermocystidium complex based on observations of fine structure. Veröff. Inst. Meeresforsch. Bremerhaven Suppl. 5: $45-63$

Schlumberger, H. G. (1950). Polycystic disease (mesonephros) in the goldfish. Arch. Pathol. 50: 400-410

Stolk, A. (1956). Polycystic kidneys in the veiltail Carassius auratus var. japonicus bicaudatus Zernecke. Proc. K. ned. Akad. Wet. Ser. C. 58: 70-73

Van de Moer, A., Manier, J.-F., Bouix, G. (1986). Étude ultrastructural de Dermocystidium macrophagi n. sp., parasite intracellulaire de Salmo gairdnen Richardson, 1836. Annls Sci. nat. (Ser. Zool.) 8: 143-151

Voelker, F. A., Anver, M. R., McKee, A. E., Cassey, H. W., Brenniman, G. R. (1977). Amebiasis in goldfish. Vet. Pathol. 14: 247-255

Wakabayashi, H., Kaku, M., Nakajima, K., Egusa, S. (1969). Kidney enlargement of goldfish. Fish Pathol. 4: 47-51

Wootten, R., McVicar, A. H. (1982). Dermocystidium from cultured eels, Anguilla anguilla L., in Scotland. J. Fish Dis. 5: $215-222$

Manuscript first received: December 1, 1991 Revised version accepted: February 26, 1992 